\title{
Mercury sensitivity of staphylococci
}

\author{
SUSAN M. GREEN ${ }^{1}$ \\ From the Air Hygiene Laboratory, Central Public Health Laboratory, Colindale, London
}

SYNOPSIS The technique devised by Moore (1960) for determining the sensitivity of staphylococci to mercuric chloride was investigated and the effect of variations in the medium determined. An alternative technique, in which paper discs impregnated with phenyl mercuric nitrate are used, was found to give identical results.

Three hundred and eighty-six out of 717 staphylococci from various sources in hospital were resistant to mercuric chloride, most of the strains belonging to phage types that have commonly produced epidemics.

Only five of 73 strains from septic lesions in R.A.F. recruits and only three of 380 strains from healthy nasal carriers among R.A.F. recruits were resistant to mercury.

This paper records an investigation designed to extend the observations made by Moore (1960) on the correlation between the apparent epidemic potentiality of strains of Staphylococcus aureus and their resistance to mercuric chloride.

\section{MATERIAL}

One thousand and ninety-seven strains of staphylococci were examined. These fell into two groups: 1 Seven hundred and seventeen staphylococci, which had been phage-typed, comprised 73 strains from septic lesions in R.A.F. recruits, 34 strains from the noses of healthy R.A.F. recruits, and 610 strains sent for phage-typing to the Staphylococcal Reference Laboratory, coming from septic lesions, infected persons and their contacts, in the British Isles and abroad. When several strains of the same phage type were isolated from one source at about the same time, they were counted as belonging to a single incident (Table I). 2 Three hundred and eighty strains of staphylococci, which had not been phage-typed, came from the noses of healthy R.A.F. recruits.

\section{METHODS}

For the main survey, the medium described by Moore (1960) was used, that is, a 1 in 27,500 solution of mercuric chloride in peptone water agar prepared from $2 \%$ Oxoid peptone, $1 \%$ Davis agar, and $0.5 \%$ sodium chloride.

Some investigations were made into the effect of various modifications to Moore's test medium, and Moore's method was also compared with a method using paper discs impregnated with phenyl mercuric nitrate. These discs were prepared as follows:-

Received for publication 6 November 1961.

'Present address: Department of Bacteriology, Guy's Hospital Medical School, London, S.E.1.
Phenyl mercuric nitrate was dissolved in hot absolute alcohol to give a $0 \cdot 1 \% \mathrm{w} / \mathrm{v}$ solution; this was further diluted in hot alcohol to a concentration of 1 in 150,000 . Amounts of the solution, each of $0.02 \mathrm{ml}$., were dropped on to discs of blotting paper $0.6 \mathrm{~cm}$. in diameter and left overnight at room temperature to dry. Each disc contained about $1.3 \times 10^{-7} \mathrm{~g}$. of phenyl mercuric nitrate. Drops of an overnight broth culture were spread over a quarter of a $2 \%$ Oxoid peptone water agar plate to give confluent growth and a disc placed on the spread area. After overnight incubation at $37^{\circ} \mathrm{C}$. sensitive strains showed a clear-cut zone of inhibition between 0.2 and $0.3 \mathrm{~cm}$. wide around the disc whereas resistant strains grew right up to the disc.

\section{RESULTS}

MODIFICATIONS IN MEDIA Twenty strains of Staph. aureus were selected. On one batch of the standard medium, nine of these strains were mercury-resistant, nine mercury-sensitive, and the other two partly sensitive.

Changes in concentration of Oxoid peptone Media containing 1 in 27,500 mercuric chloride and $1.8 \%$, $2 \%$, or $2.2 \%$ of Oxoid peptone were prepared. Each strain was inoculated on to three areas of each of two plates poured from the same bottle of medium. Differences between $1.8 \%$ and $2 \%$ of Oxoid peptone were very slight and only apparent with the partly sensitive strains. On the medium containing $2 \cdot 2 \%$ of peptone, six out of nine of the strains which were sensitive on the standard medium showed some growth.

Changes in concentration of Davis agar Two per cent Oxoid peptone containing $0.8 \%, 1 \%$, and $1.2 \%$ of Davis agar was used to prepare 1 in 27,500 
mercuric chloride plates. The reduced concentration of $0.8 \%$ had no demonstrable effect on the growth of nine test strains but on plates with $1.2 \%$ agar five out of nine of the sensitive strains grew, although only poorly.

Make of peptone Different concentrations of Evans and Difco peptone had to be used to produce the same results as those obtained with $2 \%$ Oxoid peptone. After preliminary tests it was found, with 60 strains, that virtually identical results could be obtained with $1.1 \%$ Evans, $3 \%$ Difco, or $2 \%$ Oxoid peptone. Alternatively, if the peptone concentration was kept at $2 \%$, identical reactions could be obtained with 1 in 20,000 mercuric chloride in the Evans peptone medium, 1 in 50,000 mercuric chloride in the Difco peptone medium, and 1 in 27,500 mercuric chloride in the Oxoid peptone medium.

Neutralization of mercuric chloride in the medium The mercuric chloride could be inactivated by the addition of cysteine hydrochloride to the medium. The amount required for neutralization in plates from the three makes of peptone, standardized to give similar degrees of inhibition, was very nearly the same, suggesting that the amount of active mercuric chloride in each medium was the same.

Age of plates Plates stored overnight at $4^{\circ} \mathrm{C}$. and then used up to two days after preparation were found to be satisfactory.

MERCURY SENSITIVITY OF COAGULASE-POSITIVE STAPHYLOCOCCI Seven hundred and seventeen strains of Staph. aureus of known phage type from infected persons and their contacts in hospitals and from the hospital environment were tested for sensitivity to mercuric chloride (Table I). Three hundred and음 eighty-six $(53.8 \%)$ strains were resistant, $320(44.6 \%)$ were sensitive, and 11 were of intermediate sensitivity. The intermediate strains gave a small number of colonies on the test medium but when they wereㅡㅡㅁ retested on another batch of medium, all were com- $-\widehat{\nabla}$ pletely sensitive.

Strains in phage group I with a phage pattern of 80 or $52 / 52 \mathrm{~A} / 80$ were almost all resistant to mercuric chloride. Considering type 80 strains separately, $145^{\circ}$ strains from 47 separate incidents were tested, of $\vec{\omega}$ which $132(91 \%)$ were mercury-resistant and only? $12(8.3 \%)$ mercury-sensitive. Of the sensitive strains, three were associated with epidemic incidents in $\vec{G}$ which the remaining type 80 strains involved were $\omega$ mercury-resistant, and a further four strains were N isolated during one epidemic in a maternity hospital ${ }^{\circ}$ due to a mercury-resistant type $52 / 52 \mathrm{~A} / 80$ strain. 9 Strains of type 79 and most strains of type 52A/79were sensitive to mercury although both have been responsible for some epidemic spread. Most other ${ }^{<}$ group I strains were sensitive. Group II strains wereeo consistently sensitive to mercury, including types 71 and $3 C / 55 / 71$, which have been responsible for some spread of infection. The results from group III were less clear cut. All strains of the 'epidemic types' $83 \mathrm{~A}$ and $7 / 47 / 53 / 54$ (Williams and Jevons, 1961) anda most strains of type 75/77 were resistant to mercury, $\mathbb{Q}$ and all type $42 \mathrm{E}$ strains, which have much less commonly caused epidemics, were mercury-sensitive.? Other phage types had sensitive and resistant members, but from the information available it was not

TABLE I

\begin{tabular}{|c|c|c|c|c|}
\hline Phage Group & Phage Type & No. of Strains & No. Mercury-resistant & No. of Incidents \\
\hline I & $\begin{array}{l}80 \\
52 / 52 \mathrm{~A} / 80 \\
52 / 80 \\
52 \mathrm{~A} \\
79 \\
52 \mathrm{~A} / 79\end{array}$ & $\begin{array}{r}145 \\
142 \\
10 \\
11 \\
29 \\
53 \\
43\end{array}$ & $\begin{array}{l}132(1)^{1} \\
128(1) \\
3 \\
0 \\
0(1) \\
4(3) \\
5\end{array}$ & $\begin{array}{r}47 \\
45 \\
9 \\
11 \\
10 \\
28 \\
30\end{array}$ \\
\hline $\begin{array}{l}\text { II } \\
\text { Other group II strains }\end{array}$ & $\begin{array}{l}71 \\
3 C / 55 \\
3 C / 55 / 71 \\
3 B / 3 C / 55 / 71\end{array}$ & $\begin{array}{r}14 \\
9 \\
31 \\
8 \\
26\end{array}$ & $\begin{array}{l}0(1) \\
0 \\
0 \\
0 \\
0\end{array}$ & $\begin{array}{r}12 \\
9 \\
22 \\
7 \\
19\end{array}$ \\
\hline III & $\begin{array}{l}6 / 7 / 47 / 53 / 54 / 75 \\
6 / 7 / 42 \mathrm{E} / 47 / 53 \\
7 / 47 / 53 / 54 \\
42 \mathrm{E} \\
53 / 77 \\
75 / 77 \\
73 \\
83 \mathrm{~A}\end{array}$ & $\begin{array}{r}11 \\
15 \\
6 \\
11 \\
15 \\
15 \\
7 \\
51 \\
63\end{array}$ & $\begin{array}{l}5 \\
4 \\
5(1) \\
0 \\
15 \\
12 \\
1 \\
51 \\
21(3)\end{array}$ & $\begin{array}{r}10 \\
11 \\
5 \\
10 \\
2 \\
8 \\
6 \\
12 \\
37\end{array}$ \\
\hline & 187 & 2 & 0 & 2 \\
\hline
\end{tabular}

${ }^{1}$ Numbers in brackets are intermediate strains. 
TABLE II

DISTRIBUTION OF PENICILLIN RESISTANCE IN STRAINS TESTED FOR SENSITIVITY TO MERCURIC CHLORIDE

\begin{tabular}{|c|c|c|c|c|}
\hline \multirow{2}{*}{ Phage Group } & \multicolumn{2}{|c|}{ Mercury-resistant } & \multicolumn{2}{|c|}{ Mercury-sensitive } \\
\hline & $\begin{array}{l}\text { Total No. of } \\
\text { Strains }\end{array}$ & $\begin{array}{l}\text { No. of Strains } \\
\text { Penicillin-resistant }\end{array}$ & $\begin{array}{l}\text { Total No. of } \\
\text { Strains }\end{array}$ & $\begin{array}{l}\text { No. of Strains } \\
\text { Penicillin-resistant }\end{array}$ \\
\hline I & 29 & 23 & 73 & 19 \\
\hline II & 0 & $\mathbf{0}$ & 39 & 9 \\
\hline III & 10 & 7 & 27 & 10 \\
\hline Total & 39 & $30(77 \%)$ & 139 & $38(27.3 \%)$ \\
\hline
\end{tabular}

possible to tell whether the resistant strains were in fact more commonly associated with spreading infection than the sensitive strains.

Records were available on four epidemics occurring in one hospital due to strains of phage type 83A, $75 / 77,53 / 77 /+(54)$ and 79 (1,000 $\times$ R.T.D.). Staph. aureus had been isolated from the lesion, nose, perineum, and bedclothes of patients involved in the epidemic and from the air in the ward. All strains tested from the epidemics caused by the first three types were mercury-resistant while all the type $\mathbf{7 9}$ strains were sensitive. The number of ward patients becoming nasal carriers and the number of lesions due to the epidemic type were compared in each epidemic; the ratio of lesions to nasal carriers was found to be $1: 1.5$ for type $83 \mathrm{~A}, 1: 3.8$ for type $75 / 77$, $1: 2 \cdot 8$ for type $53 / 77 /+$, and $1: 6$ for type 79 , that is, the ratio was lowest in the epidemic due to the mercury-sensitive strain.

Only five of the 73 lesion strains from sporadic infection in R.A.F. recruits were resistant to mercury. Three of the resistant strains were phage type $\mathbf{8 0}$ and were the only representatives of this type, and the two remaining mercury-resistant strains belonged to phage group III with patterns $53 / 77$ w and 53 . Based on the findings at Colindale during 1960, these phage patterns would be described as typically epidemic, that is, associated with epidemic spread in more than $20 \%$ of the cases from which they were isolated.

Of the $\mathbf{3 8 0}$ nasal strains tested from healthy R.A.F. recruits only three were resistant to mercuric chloride: they had phage patterns $52 \mathrm{~A} / 79 / 80,187$ $(1,000 \times$ R.T.D. $)$, and 6/7/47/53/54/75/+.

The distribution of penicillin sensitivity in 178 of the strains tested for sensitivity to mercuric chloride showed that mercury-resistant strains were more likely to be penicillin-resistant than mercury-sensitive strains. The correlation was by no means complete (Table II).

COMPARISON OF PLATE AND DISC METHODS The mercury sensitivity of $\mathbf{2 0 5}$ strains sent to the Staphylococcus Reference Laboratory was tested by the phenyl mercuric nitrate disc method and the mercuric chloride plate method. There was complete agreement in the results given by the two methods.

\section{DISCUSSION}

The distribution of mercury resistance amongst the strains of Staph. aureus tested closely followed that obtained by Moore (1960) with the exception that all of 51 type 83A strains tested in this series were mercury-resistant, whereas in Moore's series only one out of nine strains was resistant. The difference may derive from differences in the criteria for recognizing this type, but it is notable that type 83A has become one of the commonest types isolated from epidemics of hospital infection in recent years (Williams and Jevons, 1961). Mercury-resistant strains belonging to typical epidemic types were frequent amongst hospital strains but were very rare in the R.A.F. recruits whose contact with hospital is probably no greater than that of the civilian population.

It was found necessary to conduct the test exactly as described by Moore, and, although small variations which arise during the preparation of a set of plates from time to time did not affect the division into sensitive and resistant strains, it was shown that a change in the agar concentration from $1.0 \%$ to $1.2 \%$, in the peptone concentration from $2 \%$ to $2.2 \%$, or in the brand of peptone used, upset the results. It is therefore necessary to include a known sensitive and resistant strain on each plate as a control. The importance of using the plates within three days of preparation was confirmed. The determination of mercury sensitivity by the use of discs impregnated with phenyl mercuric nitrate has the advantage that the results are less dependent on minor changes in the medium and the discs can be stored to be used when needed; a batch of discs kept at $4^{\circ} \mathrm{C}$. for two months showed no decrease in activity.

\section{REFERENCES}

Moore, B. (1960). Lancet, 2, 453.

Williams, R. E. O., and Jevons, M. Patricia (1961). Zbl. Bakt., I. Abt. Orig., 181, 349. 